\title{
Are medical editors responsible if articles they publish cause harm?
}

\author{
— Cite as: CMAJ 2019 January 21;191:E89-90. doi: 10.1503/cmaj.109-5680
}

Posted on cmajnews.com on Jan. 2, 2019.

$\mathbf{T}$ he fallout from a controversial analysis on statins demonstrates why medical journals must consider the potential harms of the papers they publish, according to a Danish ethicist. However, medical editors contend that some unintended harms may not be predictable or within their control.

Five years ago, the BMJ published an Analysis article that argued that statins have no overall benefit for patients at low risk of heart disease. Months later, it became the focus of a media storm when a researcher complained that the authors had overstated the frequency of adverse effects. The BMJ corrected the article, but the debate continues, with the journal pushing for an independent review of trial data. More than 200000 people in the United Kingdom have since stopped taking statins, which researchers estimate may contribute to 2000 extra cardiovascular events in the future.

Journal editors have a responsibility for such harms, says Thomas Ploug, a professor at the Centre for Applied Ethics and Philosophy of Science at Aalborg University in Copenhagen. In a paper in the Journal of Medical Ethics, he also cited the case of a Danish study that met obstacles to publication because it found that antibiotics could be useful in allevi-

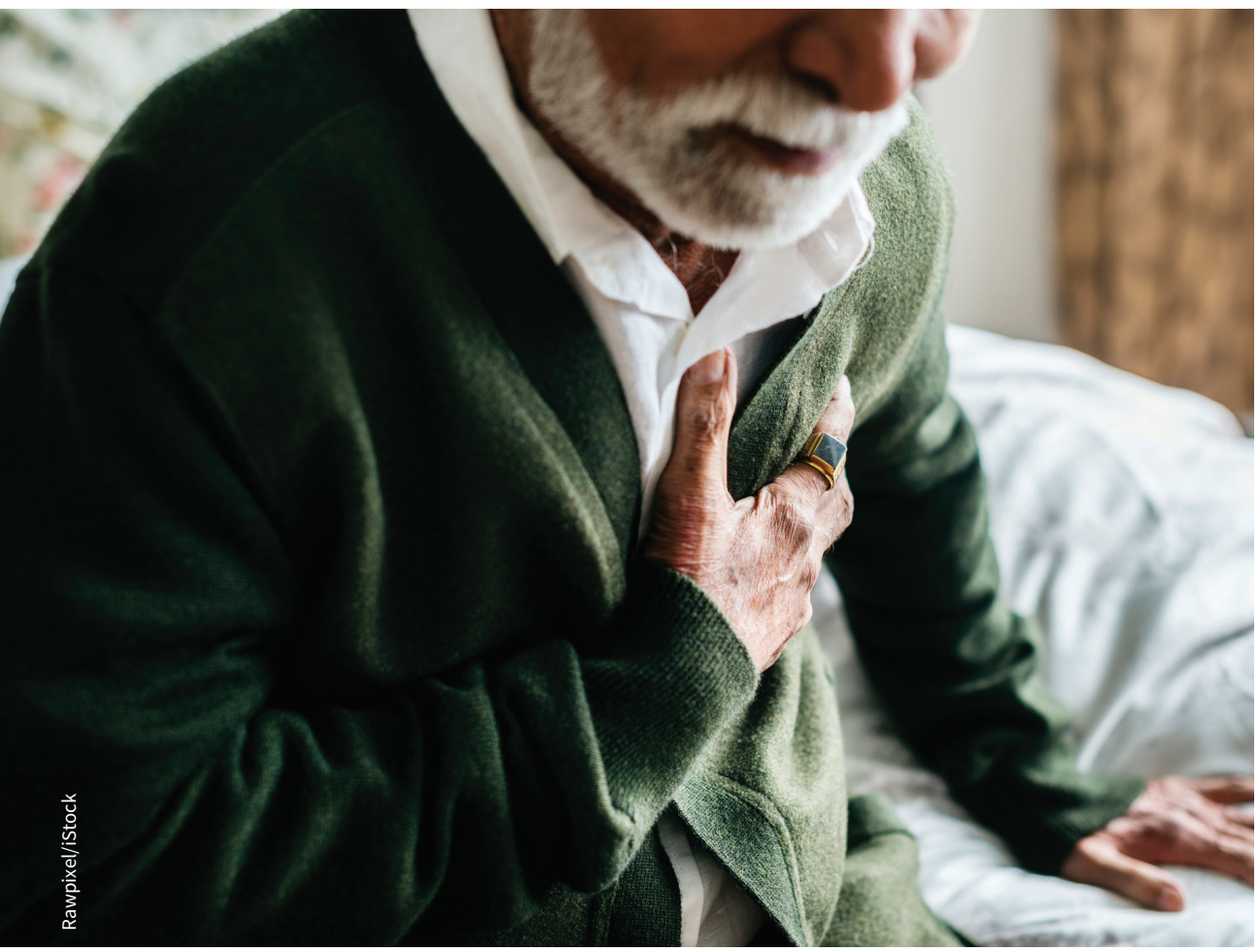

The harms of some publications can be difficult to predict, as in the case of a controversy over an article that may have led patients to stop statins. ating symptoms of a widespread chronic disease. According to Ploug, at least one reviewer noted that publishing the study could lead to increased antibiotic use and therefore to antibiotic resistance. In both cases, "it is the publishing of these studies in a scientific journal that significantly increases the likelihood of the harmful effects."

Medical editors have a responsibility as the gatekeepers to publication to avoid or minimize these harmful effects, Ploug argues. This may mean rejecting a publication or changing its content and context. For example, editors may ask authors to revise unbalanced statements or publish accompanying commentaries or press releases that explain how a paper fits into the wider medical context. Beyond a consensus not to publish research that could be used for biowarfare or terrorism, "there is little guidance for acting on this moral responsibility," Ploug told CMAJ. As such, "there is a lurking risk of arbitrary and biased editorial handling of medical research papers," he said. "To amend publication ethics codes would provide both guidance and transparency."

However, some medical journal editors contend that their primary responsibility is ensuring the integrity of research. "In a contemporary environment, I'm not quite sure anyone really serves as a gatekeeper," said Dr. Howard Bauchner, editor in chief of JAMA. "I think journal editors have a very specific responsibility about ensuring what they publish is accurate."

Of course, some topics require careful handling, Bauchner said. "Anything on autism is generally carefully looked at a second time." More complicated or controversial papers "are more likely to be 
accompanied by an editorial." And there have been rare times ("fewer than two or three" in Bauchner's tenure) when editors have rejected papers because the potential harms of publication seemed to outweigh the benefits.

However, other editors may prefer a more provocative approach, "and that doesn't mean they're not factually based," Bauchner said. Besides, it may not be possible to predict or mitigate the ripple effects of a publication. "I don't think anyone really believes an editor can control the social discourse on an article."

$B M J$ editor in chief Dr. Fiona Godlee said she didn't expect the statins article to be so controversial. "In my view, we published a piece in an academic journal raising an issue that was relevant to doctors, saying what is the evidence, let's dis- cuss this more widely between ourselves." The journal didn't issue a press release and the article was behind a paywall. When clinical debate spilled into public controversy, the nuances of the article were lost. "Statins are important in people who have high risk or already have heart disease, and it's very hard to communicate clearly that we're not talking about those people, we're talking about people for whom the benefit-to-risk ratio is much less straightforward."

In addition to correcting the article and another paper containing the same error, Godlee published an editorial to provide more context and passed the decision of whether to retract the articles to an independent panel. The panel found no reason to retract and concluded that the BMJ's handling of the papers was "appropriate and that its processes were timely and reasonable."

For all the ways an editor may try to influence the reception of an article, none are "by any means a guarantee that things won't get out of hand," Godlee said. But just because a conversation is difficult, "that's not a reason to give up on the thing."

For example, some people consider it "irresponsible" to scrutinize vaccine safety and efficacy lest they provide fodder for the anti-vaccination movement, but Godlee said that avoiding such topics undermines public trust. "Provided the debate is in the right way, in the right context and forums, argued adequately and responsibly, I don't think there should be anything we can't discuss."

Lauren Vogel, CMAJ 